\title{
Study on three-level dynamic management mode of student organizations in Hefei University of Technology Xuancheng Campus
}

\author{
Zhige $\mathrm{Wu}$ \\ Hefei University of Technology, Xuancheng, 242000, China
}

Keywords: student organization; interest group; club; dynamic management; mode

\begin{abstract}
: due to large college student organizations and incomplete structural system, effective means should be taken to get to the heart and drive overall development, enhance organization atmosphere, make organizations own stronger cohesive force and centripetal force and achieve significance of participation in organizations by college students. The establishment of three-level dynamic management mode can effectively enhance organization management. Three levels refer to interest group, student organization and club. Personal potential can be motivated through the organizations, and personal strong points can be exerted.

As the reform of higher education deepens continuously, increasingly booming student organizations play a more and more important role in quality-oriented education, self-education, self-management and self-service of students. College student organization is not just a every good form to carry out ideological and political education for college students, but also a main force of campus culture construction and important base for "three-self" education of college students.

With the change in economic mode and continuous development of market economy, a kind of new culture and new trend is permeating in colleges. Thus, thinking of college students is broader and their values also change. Student organization is another course of colleges. It plays a vital role and can change development and growth of a person. In particular, China is advocating cultural development and enhancing ideological education work of college students. According to advantages of student organizations, it is required to know significance and values of student organizations, establish three-level dynamic management operation mode, carry out comprehensive development education for college students and make college management system more perfect and campus cultural atmosphere stronger.
\end{abstract}

\section{College student organization building features}

\section{Diversity of activity contents}

College students participate in student organizations voluntarily and choose them according to their interests and hobbies. Organization forms are various. In each semester, each organization will arrange numerous activities for the choice of students and provide overall development for them so as to display personal charm and strengths. Besides, college student organizations are managed and organized by students themselves. So, college student organizations will change with the development of the outside world. In different times, the themes are also different. Therefore, college student organizations are typical and the products of development of times. Activities of the organizations should change with times to reflect features of times. The activities must meet growth and development direction as well as interests and hobbies of college students. In this way, more college students will be attracted to participate in the activities.

\section{Spontaneity and flexibility}

The setup of student organizations just needs the approval of student management department. They are composed of the students with the same interests and strengths. Student organizations aim to provide a stage for students to show themselves. The founders just need to organize management work, and other members can reveal their talents actively and enthusiastically. So, student organizations are characterized by spontaneity and diversity of activity forms. The scale and number of a student organization depend on specific conditions. The time and space of activities are also random. The forms and contents of activities are creative and flexible. 


\section{Universality of members}

Colorful activities provide a stage for college students to show themselves and enrich their extracurricular life. The students from different nations, majors and grades are organized together due to the common interests. Therefore, the groups of the organizations are of a wide range. Besides, the organizations are organized, managed and operated by students. The activities are arranged and implemented by themselves. The affairs are also completed through their negotiations. All these fully reflect independent innovation consciousness of college students and effectively drive their quality development.

\section{Significance of college student organizations}

\section{Beneficial to enhancing campus culture construction}

College student organization serves as a significant part. Its organization management can reflect culture construction of a college. Although the student organization is just a part of campus, it is representative and reflects campus culture atmosphere and cultural quality.

\section{Beneficial to facilitating healthy growth of college students}

Society keeps improving, and people's pace of life becomes increasingly fast. Thus, there are many factors influencing physical and psychological health of college students. But, college student organizations provide space for their communication and exchange. Since members in an organization have the same interests, they can find bosom friends and enhance self-confidence. Student organizations have the force to motivate personal potential and contribute to edifying the students lacking enthusiasm. Besides, student organizations can make students feel relaxed and happy and promote affective interaction and cultural quality cultivation of students.

\section{Beneficial to promoting socialization of college students}

Student organizations provide a social stage for students. For college students at the age of about 20, they need a platform which further approaches the society to help them adapt society faster. Student organizations provide a platform for training themselves. Three-level dynamic management mode can effectively promote social adaptation ability of college students and improve their cultural quality.

\section{Status survey of student organization management in our campus}

\section{Survey samples}

Basic information of student organizations is known comprehensively through a questionnaire survey. A total of 2000 questionnaire were distributed and 1956 questionnaire were collected. Among the respondents, student organization administrators account for $32.5 \%$ and members account for $48.7 \%$. The remaining students do not join any organization. This survey is a random survey. The proportions of students in various grades are different. The proportions of students in Grade 1, Grade 2, Grade 3 and Grade 4 are as follows: 18.2\%, 64.8\%, 13\% and 4\%.

\section{Current situations of student organization development and management in our campus}

At present, the scale of student organizations in our campus is on the rise, and the number of members also increases. The types of organizations also rise. According to the survey, college students who participated in student organizations account for nearly $60 \%$. On the average, each student joins about 2 organizations. A few students join cross-campus organizations and network organizations. Therefore, rich campus activities are representative for campus culture. But, there are serious defects in current campus organizations:

(1) Management and operation system is imperfect. Although each college has campus management system and standards, but they cannot be well implemented. Some colleges fail to carry out strict investigation when the organization is set up, so the management mode of most organizations is the same. Most organizations imitate others' organization management system. No 
system and regulations are established during the setup of the organizations. Some colleges conduct loose investigation of organizations. This is because the colleges have no operable assessment system or professional examiners. So, organizations lack competitiveness.

(2) The development is short of basic guarantee. Currently, the most important cause which hinders the development of student organizations is that colleges fail to input more funds and the activity space is limited. These cannot meet students' requirements. Organization funds partly come form the college and largely raised by students. The insufficiency in funds is a common difficulty. So, the types of activities held in campus are limited. Moreover, poor quality causes expected results are not achieved. In addition, most organizations have no fixed activity space, so the management difficulty is large. Site use cannot be well solved by students themselves and Youth League Committee. Colleges should give strong support. Relevant departments should coordinate with the development of organizations to ensure organization development and improve existence value of organizations.

(3) Management system is imperfect. Colleges fail to see clearly significance and nature of originations and consider students should found, manage and organize activities by themselves. Thus, colleges do not give proper management and evaluation of the activities held by organizations so that students manage organizations in a disorderly manner. Without guidance from professionals, the value and quality of organizations cannot be ensured. Additionally, the persons in charge of organizations can be changed at will, lacking fair competition. There are also problems in financial management. Consumption of funds is not transparent. Thus, funds are used at random. Such situation that there are many activities this year and $n$ activity in next year may occur. Therefore, without a perfect system, organization management will adversely influence organization operation. Furthermore, due to unclear cognition, some relevant departments have no rational planning and development direction. Thus, there are no rules to guide organization development.

\section{Measures to establish three-level dynamic management mode for student organizations in our campus}

\section{To perfect international management system}

The establishment of management system can effectively facilitate organization development and provides an effective guarantee. Only when three-level dynamic management operation more and perfect system are established can organization development be promoted in a well-organized way. Firstly, establish the department and procedure for examination and approval of campus organizations and well grasp examination and approval of campus organizations. During an organization submit the application, it should provide a set of management scheme and system and seek an adviser who should propose feasible measures, if necessary. Besides, it should be subordinate to a department to provide certain guarantee. There should be fund source, and administrators should abide by rules and be strict with themselves. Secondly, it is required to specify management responsibilities. The superior department of the organization should participate in management and give guidance and suggestions. The organization should obey organization and management of Youth League Committee of the college. Thirdly, normative management methods can be proposed. Certain regulations can be taken. The regulations include some methods to deal with application, funds and activity implementation.

\section{To set up three-level dynamic management operation mechanism}

It is required to set up three-level dynamic management operation mechanism, make it operate effectively through practices, seize features of the organization, find out the factors influencing organization development and grasp the core to drive overall development, enhance organizational atmosphere, make the organization have stronger cohesive force and centripetal force, improve students' quality and sentiment and achieve significance of joining organizations. Three-level dynamic management mode can enhance students' organizing and coordinating ability, give full play to the functions of organizations. Three-level dynamic management can make organizations operate orderly and have restrictive functions for each planning and each link of activities. It can 
promote rational arrangement of activities and catch the core. Students arrange activities in their spare time, which will not influence studies. Besides, the activities should pay attention to planning and packaging, specify development objective and direction, combine specific social events and hot topics as activity contents and hold significant and connotative activities so as to make activities connected with society and achieve socialization. Each member should participate to improve overall quality of organizations, enhance moral cultivation, fully train personal abilities and achieve self-value.

\section{To implement organization management evaluation mechanism}

In three-level dynamic management mode, scientific evaluation system must be established. This is an essential link of organizations. Scientific evaluation system can make an organization operate normally and have representativeness and directivity. Traditional organization assessment mainly includes three aspects: scale, number of activities and regulations. After three-level dynamic management system is implemented, dynamic evaluation system aims to specify development direction and objective of an organization according to certain regulations on administration. A full set of dynamic management system should be formulated through process control and effect evaluation. It is required to highlight innovation ability of organizations and ensure setup significance. Besides, three-level dynamic reporting system should be set up, such as weekly report, monthly summary and annual assessment. When an organization is preparing an activity, each link should be implemented. All members must abide by the system from planning to implantation and report work dynamics to administrators regularly. The management department should summarize the information reported and propose feasible suggestions to control the whole process of the activity.

\section{To construct a platform for exchange and development}

As market economy and times develop continuously, higher education system is also changing. To make colleges effectively operate and better provide a healthy and upward platform for students, colleges must carry out three-level dynamic management mode. Such mode can promote exchange and communication among students. Besides, organization system should change correspondingly from closed type to open type. If socialization construction is added, communication among organizations, between organizations and the college and between can organizations and the society can be expanded. Organization resources and advantages should be rationally utilized to promote development of other activities. Students' independent innovation capability, organizing and coordinating ability should be cultivated through communications. Moreover, it is required to broaden students' view, develop their thinking ability, train their self-dependent innovation and practical ability, make the origination develop in a better manner, make students blend in the society and know the society fast as well as enhance their social adaptation ability.

\section{Conclusions}

The setup of three-level dynamic management mode effectively enhances harmonious development of organizations. Hierarchical management mode is a key part of dynamic operation of organizations and contributes to strengthening sense of responsibility of administrators. It provides guarantee for orderly operation of the organization and lay s favorable foundation so as to promote students' development faster. Three-level dynamic management mode is a complex management system. The contents it covers are diversified, such as organization and management system, training system, cultural quality training system, brand activity planning and implementation as well as guarantee system. Under three-level dynamic management mode, it is required to establish correct values and faith, promote and fuse mutually so as to make subsystems of three-level dynamic management operate harmoniously.

\section{References:}

[1] Zhou Changkui, Working thought and activity scheme of college student associations as well as 
experience reference manual of famous universities [M]. Beijing: China Youth Publishing House, 2011:1-125.

[2] Cheng yahong, Shang Dan, Main problems and improvement ways of college association construction [J]. Journal of Changchun University of Technology, 2011,(02):24-25.

[3] Chen Jing, Hu Huafeng, Curent situation and development strategy of college student associations [J]. Researches in Medical Education, 2010,(03):24-26.

[4] Dai Ying, Gao Ming, Zhang Quancheng, Marketing feasibility analysis of college student associations [J]. Technology and Market, 2010,(03):39-41.

[5] XU Wenzheng, Qiao Wanmin, Promotion of scientific development of college student associations guided by scientific development perspective [J]. Journal of Shong Youth Administrative Cadres College, 2009, (02):89-91.

[6] Kong Fanbin, From limiting freedom of association to supervising public liability - legitimacy of organization control by Chinese government and its institutional reform $[\mathrm{J}]$. Chinese Public Administration, 2005,(02) :32-37

[7] Yang Zhou, Managemnt of college student associations under perspective of organizational sociology [D]. Jilin University, 2008

[8] Chen Na, Liu Wenchao, Study on connotative development dynamic mechanism of Hebei higher education [J]. Career Horizon, 2012(04)

[9] 2005(04) Liu Shufen, Zhang Shuqin, Value features of contemporary college students and their education guidance [J]. Journal of Hebei Institute of Physical Education 